\title{
A SIMPLE MODEL FOR SHEAR CRACKING AND FAILURE IN COMPOSITE MASONRY
}

\section{S. C. Anand* and D. J. Stevens**}

"Clemson University, Clemson, SC 29631, USA
$* *$ Vought Corp., Dallas, TX 75062, USA

\section{ABSTRACT}

A two-dimensional finite element model developed earlier by the authors to compute stresses and strains in composite masonry walls subjected to inplane external loads under linear elastic conditions is developed further in this paper to incorporate the cracking and failure of the collar joint. A simple failure criterion is proposed which mobilizes resisting friction forces due to yielding of the horizontal reinforcement. It is shown with the help an example that the growth of the interface crack can be arrested once enough resisting forces have be

\section{KEYWORDS}

Composite masonry; two-dimensional finite element model; collar joint cracking; failure criterion; bed reinforcement; shear friction.

\section{INTRODUCTION}

Composite action in a masonry wall is obtained when the two independent wythes are connected together by metal ties and the cavity between the two wythes is grouted as shown in Fig. 1. For the two wythes to act together, it is important that the collar joint is strong enough to resist the shearing stresses induced in it. A quasi two-dimensional finite element model has previously been proposed by the senior author that is capable of predicting the shear stresses in the collar joint (Anand and Young, 1982). In that model, shearing stresses caused by inplane loads applied at one wythe were felt to be most significant and were only considered. No attempts were made to model the phenomenon of cracking in the collar joint.

A large amount of effort has been directed to modelling masonry and reinforced concrete with the finite element method. Specifically, the phenomena of cracking and crack propagation have received special attention (Chen, 1982 Page, 1978). There is no evidence, however, that analytical models have as yet been developed to predict cracking in composite masonry walls. A simple 

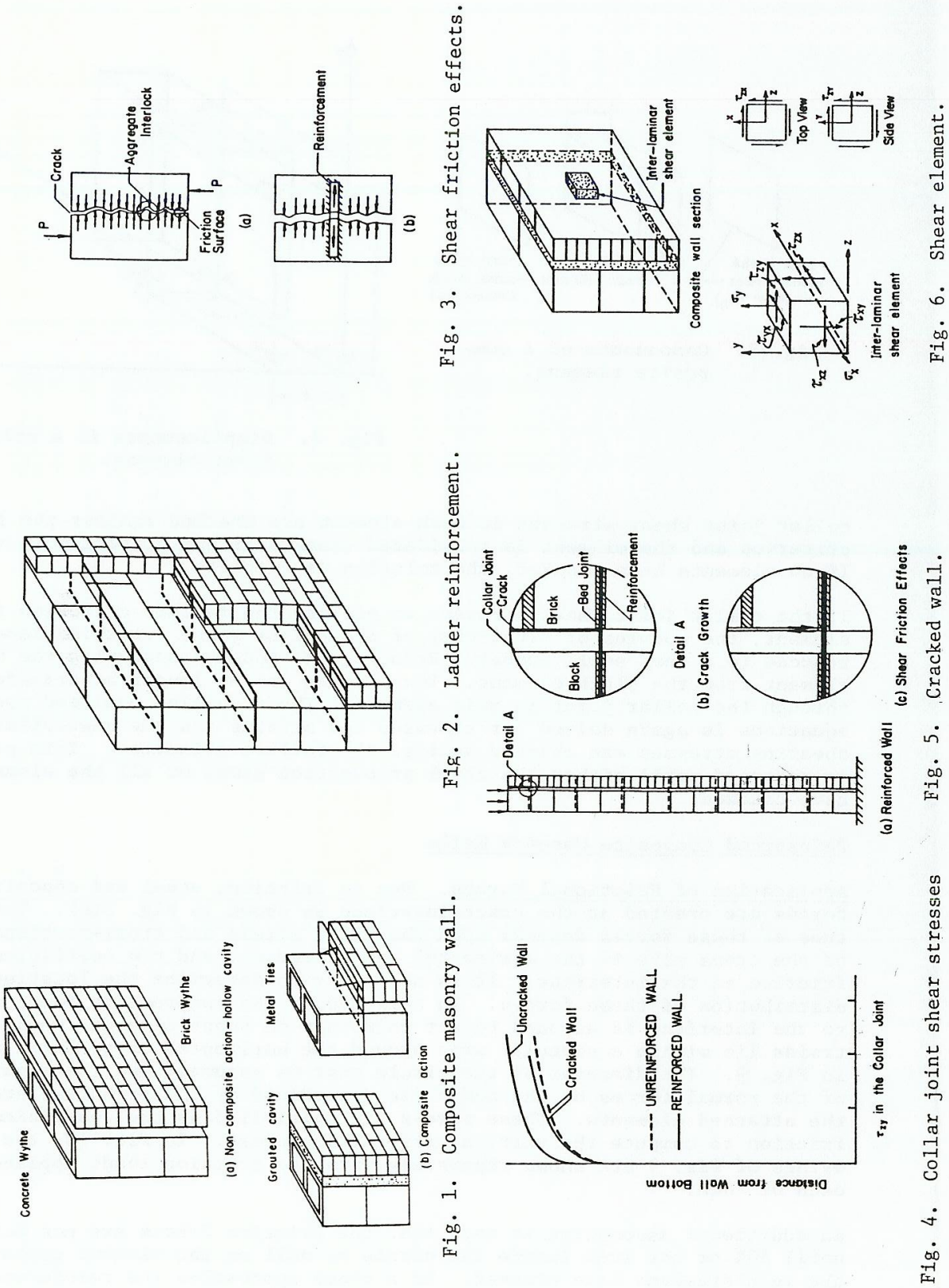

model to investigate the phenomenon of cracking which includes the effects of horizontal reinforcement is proposed in this paper.

GENERAL CONSIDERATIONS

Composite masonry walls are often reinforced with the ladder type of reinforcement that lays across the bed joints of the block and brick wythes and is placed in every other layer of concrete block as shown in Fig. 2. The diameter of the steel wire varies from 9 gage to $3 / 16$ in. $(4.75 \mathrm{~mm})$ and the cross pieces of wire are spaced 15 in. $(38.1 \mathrm{~cm})$ on center.

Frictional Forces at a Crack. Shear friction in reinforced concrete occurs when compressive stresses act normal to a crack surface, keeping the surfaces on either side of the crack in contact, as shown in Fig. 3(a). Any tangential movement of one face with respect to the other is resisted by the friction and aggregate interlock. The compressive normal stresses can be created by either the imposed loading or the presence of the reinforcement. Fig. 3(b) shows a length of reinforcing steel that is in tension due to the opening of the crack. Alphonso and Brown (1979) measured this crack distance for grouted reinforced masonry prisms and determined that the crack width was large enough in their specimens to bring the reinforcing steel to yield. Thys, the magnitude of the compressive force could be assumed to equal to the yield stress of the steel multiplied by its cross-sectional area. Knowing the compressive force applied by the yielded steel and assuming an appropriate coefticient of friction, the

Description of Crack Growth. The shear stress distribution in the collar joint due to loads applied to the block wythe of an unreinforced uncracked wall is shown in Fig. 4. At some increased load, the peak shear stress becomes larger than the bond strength of the two interfaces and a crack forms at either the collar joint-brick interface or the collar joint-block interfe face depending upon the same since the load must still be transferred to the brick wy the. The only change is that the shear stress distribution has moved downwards with the maximum shear stress starting at the crack tip. As the peak shear stress value remains the same, the crack propagates downwards in the wall until a wythe is completely separated from the collar joint.

Walls that contain reinforcement can possibly resist crack growth. A reinforced wall in which the crack has reached the reinforcement is shown in Fig. 5. As the crack crosses the reinforcement, the frictional forces as described in the previous section are activated to resist the crack. These equal and opposite forces applied to both sides of the crack are shown in Fig. 5 and the corresponding shear stress distribution is shown in Fig. 4. The shape of the shear stress diagram remains the same but the peak shear stress value is lower because of the action of the friction force. If enough friction force can be developed to drop the peak shear stress below the maximum shear strength of the interface, the crack will stop growing.

ELASTIC ANALYSIS OF AN UNCRACKED WALL USING THE COMPOSITE ELEMENT

In general, the external loads are applied to the inner concrete block wythe. A portion of these loads are transferred to the outer brick wy the through the collar joint creating shearing stresses as shown in Fig. 6. 


\section{Stiffness Matrix of a Composite Element}

The finite element method, in general, is well known and no attempts are made here to explain it in detail. Nevertheless, the development of the wythe faces ness matrix for a composite element consisting of the two element sermulation of a composite stiffness matrix representing the inplane the shearing stiffness matrix combining these stiff collar joint, and finally stiffness matrix. It is assumed linearly elastic, and out-of

Determination of displacements and stresses in wythes due to inplane loads can be accomplished by the plane stress finite element analysis in which the governing stiffness matrix $\mathrm{k}$ relates fores The three components of a composite element and element stiffness matrices, $k$ for the front ary are standard inplane stiffness matrices which may an element text. Shear deformation of the collar joint found ln any finite Fig. 8 and is composed of displacements in the $x$ and eleme displacement relations for the collar joint shear element are give Forceshear stiffness matrix $k$ which may be found in Anand and Young (1982).

The superposition of the two wythe element stiffness matrices and the colla ness matrix which is given by

$$
\underset{\sim c e}{k}=\left[\begin{array}{cc}
k_{f} & 0 \\
0 & k_{b}
\end{array}\right]+k_{s h} \text {. }
$$

\section{Calculation of Displacements, Strains, and Stresse}

Using the stiffness matrix of a composite element, the stiffness matrix for a finite element model of the complete wall can be assembled leading to Shearing strains ins which are solved for the nodal point displacements. using the shearing elche calculated by Inplane stresses in the by using the plane- inplane strains the collar joint responding shearing strains.

\section{CRACK MODELLING}

Unreinforced Composite Masonry Walls

Failure Criterion. To keep the model simple, the failure criterion for cracking of the collar joint is based only on the two shear stresses $\tau$ and $\tau_{z y}$

$$
\tau_{\max } \leqq \sqrt{\left(\tau_{z x}\right)^{2+\left(\tau_{z y}\right)^{2}}}
$$

where $\tau_{\max }$ is the failure shear stress determined experimentally.

Solution Procedure. The finite element model of the initially uncracked wall is solved for the strains and stresses due to the applied loads.

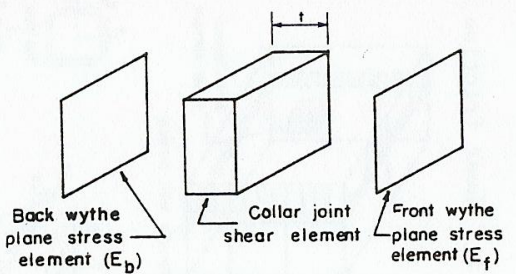

Fig. 7. Components of a composite element.

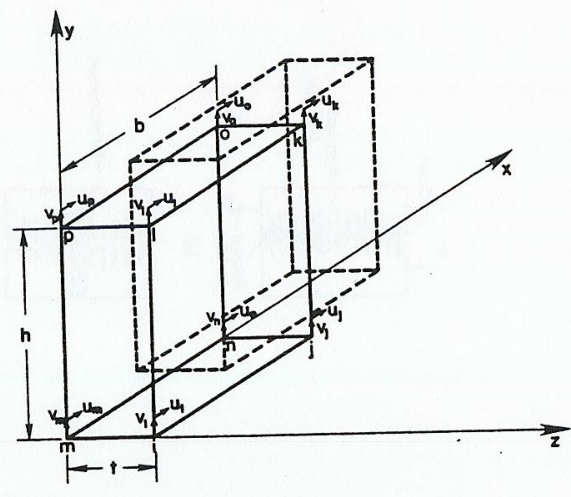

Fig. 8, Displacements in a collar joint element. collar joint shear stresses in each element are checked against the failure cracked if the criterion is violated. If no elements have cracked, the solution is complete.

If the collar joint shear stresses do violate the failure criterion in an element, the modulus of elasticity of the collar joint for this element is reduced to a very small number. Reducing the modulus uncouples the brick element from the block element. Thus, loads can no longer be transferred through the collar joint in this element. The resulting modified system of equations is again solved for stresses and strains and the new collar joint shearing stresses are checked against the failure criterion this procedure is repeated unt

\section{Reinforced Composite Masonry Walls}

Application of Frictional Forces. Due to friction, equal and opposite forces are created at the crack interface as shown in Fig. 5(c). The magnitude of these forces depends upon the yield stress and cross-sectional area of the cross wire in the horizontal reinforcement, and the coefficient of friction at the interface. It is necessary to determine the location and distribution of these forces. In this model, the compressive force normal to the interface is assumed to act uniformly on those elements whose centroids lie within a circular area around the horizontal cross wire, as shown in Fig. 9. The diameter of the circle must be assumed, and the magnitudes of the normal forces on the nodes are determined by the tributary areas of the attached elements. These forces are multiplied by the coefficient of friction to compute the vertical frictional forces. In Fig. 10, the two wythes of Fig.

An additional assumption is made that the friction forces are not activated until $50 \%$ of the area inside the circle as well as the element containing the reinforcement have cracked. If a crack approaches the reinforced section of a wall at an angle, the activated frictional forces will try to resist the progress of the crack by acting in a direcion opposite to that of the crack growth. 


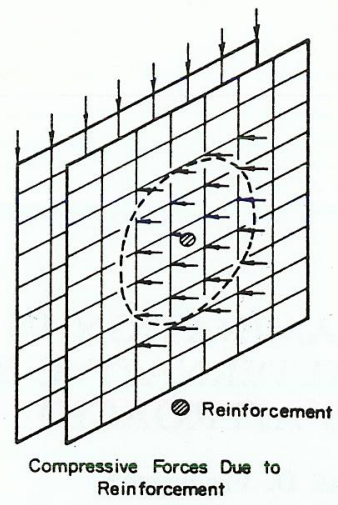

Fig. 9. Assumed circle of compressive force.

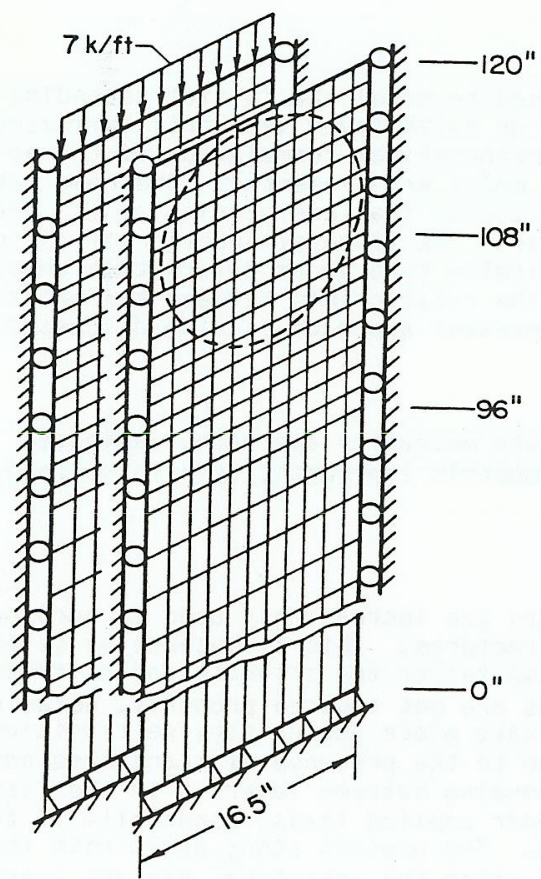

Fig. 11. Finite element mesh.

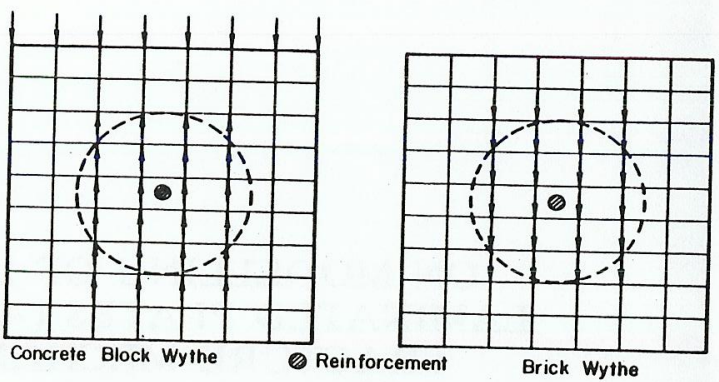

Fig. 10. Friction forces in brick and block wythes.
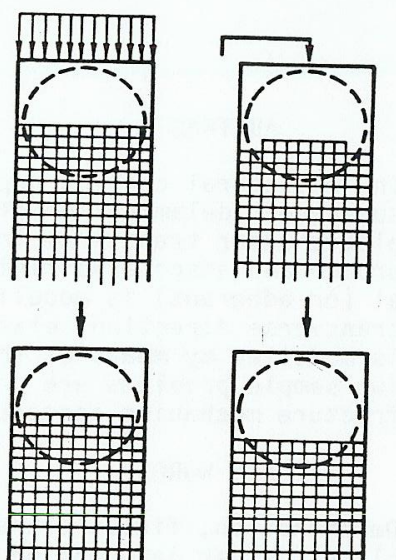

H+m+\#+1
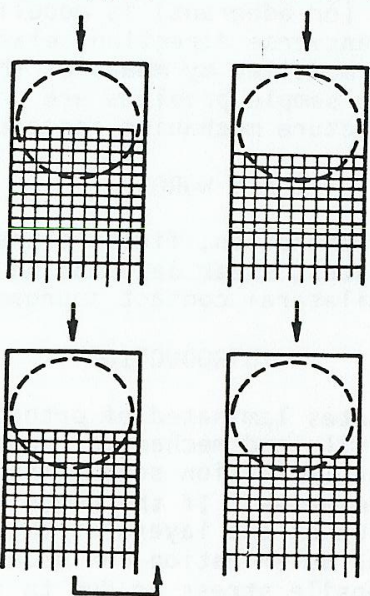

Fig. 12. Crack growth in a reinforced wall.
The solution procedure for a reinforced composite masonry wall is similar to that for an unreinforced wall except that the frictional forces are activated elements crack.

\section{EXAMPLE PROBLEM}

To examine the performance of the proposed cracking model, an example of a reinforced composite masonry wall is presented. The mesh selected for the model is shown in Fig. 11. The moduli of elasticity of the brick and block
wythes, and grout used in the analysis are given collectively in Table 1. wythes, and grout used in the analysis are given collectively in Table
The cracking shear stress in the collar joint is assumed to be $50 \mathrm{psi}$ The cracking shear stress in the collar joint is assumed to be 50 psi (3.75 103 and 140 (3.7r m at a the tion is 0.40 . The block leterine a priori to insure that the cracks would extend past the reinforcent assumed to be 16 inches $(40.64 \mathrm{~cm})$.

TABLE 1. Material Properties

\begin{tabular}{|l|c|c|c|r|c|}
\hline \multirow{2}{*}{ Masonry Type } & \multicolumn{2}{|c|}{ Thickness } & \multicolumn{2}{c|}{ Elastic Modulus } & Poisson's \\
\cline { 2 - 6 } & in & \multicolumn{1}{c|}{$\mathrm{cm}$} & $\mathrm{ksi}$ & \multicolumn{1}{c|}{$\mathrm{Nm}^{-2}$} & 0.25 \\
\hline Brick & 4 & 10.16 & 2,000 & $13.78 \times 10^{9}$ & 0.25 \\
Concrete Block & 8 & 20.32 & 1,000 & $6.89 \times 10^{9}$ & 0.25 \\
Grout & $3 / 8$ & 0.95 & 1,800 & $12.40 \times 10^{9}$ & 0.20 \\
\hline
\end{tabular}

Results

The resulting crack growth is shown in Fig. 12. Because the crack will extend freely down the wall until it meets some resistance, the elements above the reinforcent are shown initially cracked in the first figure of the sequence shown in Fig. 12. At this stage, $50 \%$ of the area within the circle is cracked and the crack has progressed past the center of the circle. Consequently, friction forces are activated at the nodes of the cracked elements during further solutions. This procedure is continued, leading to additional cracked elements as shown in the sequential steps in the figure. Cracking in this example stops when sufficient friction forces have been mobilized and the maxim cracking shear stress.

CONCLUSIONS AND RECOMMENDATIONS

A simple crack modelling technique that uses the composite element has been developed in this paper which can be applied to reinforced and unreinforced developed in this paper which can be applied to relnforced and unreinforce inforcent in a composite masonry wall can arrest the growth of a crack in the collar joint. By changing the diameter of the circle representing shear friction effects, the reinforcement size and strength, and the coefficient f friction, the user can approximate the actual behavior of any reinforced composite masonry wall. 
ACKNOWLEDGEMENTS

The research reported in this paper was supported by Grant No. CEE - 802676 from the National Science Foundation. The financial support of NSF is gratefully acknowledged.

\section{REFERENCES}

Alphonso, B., and R. H. Brown (1979). Shear Friction Design in Reinforced Masonry. Proceedings, Symposium on Behavior of Building Systems and Building Components, Vanderbilt Univ. Nashville, Tennessee, USA.

Anand, S. C., and D. T. Young (1982). Finite Element Model for Composite Masonry. J. Struct. Div., ASCE, 108, 2637-2651.

Chen, W. F. (1982). Plasticity in Reinforced Concrete. McGraw-Hill, New

(1978). A Finite Element Model for Masonry. J. Struct. Div. ASCE, $\frac{104}{D}, 1267-1284$

Methelopment and Application of the Finite Element Method to the Modelling of Composite Masonry Walls. M.S. Thesis, Civil Engineering, Clemson Univ., Clemson, S.C., USA. 